\title{
Matrizes de Dependências Aplicadas ao Controle de Disponibilidade em Cascatas de Usinas Hidrelétricas
}

\author{
Gustavo M. Alfaro ${ }^{1}$ Dany S. Dominguez Gabriel Fornari \\ Programa de Pós-graduação em Modelagem Computacional em Ciência e Tecnologia \\ Departamento de Ciências Exatas e Tecnológicas, Universidade Estadual de Santa Cruz \\ Rodovia Jorge Amado, km. 16, 45.662-900, Ilhéus-BA. \\ E-mail: gmonne@live.com ㅇdominguez@gmail.com gabrielfornari@gmail.com
}

\begin{abstract}
RESUMO
$\mathrm{Na}$ atualidade, o crescimento da economia e da população mundial está diretamente relacionado ao consumo de energia, elemento que contribuiu a fazer dos sistemas de geração e transmissão de energia uns dos mais complexos setores industriais. No Brasil, o setor energético foi decisivo no desenvolvimento econômico alcançado nos últimos anos, liderado basicamente pelas usinas de geração hidroelétrica, que representam um $75,2 \%$ da geração total de energia elétrica do pais [1].
\end{abstract}

A geração hidrelétrica destaca-se pelo baixo custo e impactos ambientais consideravelmente inferiores a outras formas de produção. Em detrimento, estes sistemas são caraterizados pela constante degradação dos seus componentes produto do regime adverso de trabalho, e devem ser rigorosamente monitorados por operadores e analistas de manutenção, tentando minimizar a ocorrência de falhas que provoquem interrupções no serviço.

Visando apoiar o trabalho de operação e manutenção, tem sido desenvolvidas na indústria várias metodologias e modelos de simulação que avaliam a disponibilidade e confiabilidade de sistemas [5], [6]. Estas metodologias têm sido aplicadas de acordo a normativas, tais como, Manutenção Orientada por Confiabilidade [7], e Gerenciamento de Ativos Físicos [2].

Neste trabalho é apresentado um método qualitativo baseado no uso de matrizes de dependências e técnicas de varredura para avaliar a disponibilidade de sistemas hidrelétricos de geração. O Método de Matrizes de Dependências (MMD) [3] classifica hierarquicamente os componentes do sistema objeto de estudo, os equipamentos mais simples são Componentes de Baixo Nível (CBN), e os elementos que representam sistemas e subsistemas são Componentes de Alto Nível (CAN). Em seguida, a estrutura do sistema e suas relações funcionais são mapeadas em uma matriz de dependências, e partindo de um vetor de elementos indisponíveis é possível executar um algoritmo baseado em heurísticas que computa a disponibilidade do sistema global. $\mathrm{O}$ algoritmo de varredura contempla duas etapas, a propagação das dependências diretas e a propagação das dependências indiretas ou aninhadas. A disponibilidade do sistema é oferecida segundo uma escala qualitativa, baseada em cores, que inclui os estados disponíveis, degradado, muito degradado e falhado.

A propagação de estados indisponíveis considera a existência de redundância de componentes em sistemas com alto risco, daí que no caso de existir dois componentes redundantes, e um deles estiver "indisponível", o estado propagado ao subsistema vai ser "degradado". Outra caraterística do método é a quantização dos elementos redundantes presentes em um subsistema, critério geralmente preestabelecido pelos analistas de risco, e que possibilita estabelecer um grau de maior precisão no nível de degradação que pode atingir um subsistema.

\footnotetext{
${ }^{1}$ Bolsista de mestrado da Fundação de Amparo a Pesquisa do Estado da Bahia (FAPESB)
} 
O algoritmo de varredura e as estruturas de dados utilizados no MMD garante um Consumo de Memória (CM) definido pela expressão:

$$
C M^{M M D}=N_{C A N} N_{D E P},
$$

onde $N_{C A N}$ é o número de CANs do sistema, e $N_{D E P}$ é o número máximo de dependências para um CAN.

O Número de Operações do Algoritmo (NOA) pode ser aproximado pela frequência de execução da operação dominante [4], sendo expressado na seguinte forma:

$$
N O A^{M M D}=N_{C A N} N_{D E P}\left(N_{F A L}+N_{C A N}\right),
$$

onde $N_{F A L}$ é o número de CBNs indisponíveis na condição inicial. A equação anterior considera que as linhas da matriz de dependências estão ordenadas conforme o nível hierárquico de cada CAN, de forma que as linhas superiores correspondam aos elementos mais significativos do sistema. Dessa forma o número de operações associado à ordenação $\left(N O A^{O R D}\right)$ das linhas da matriz de dependências usando o método QuickSort é definido pela expressão:

$$
N O A^{O R D}=N_{C A N}^{2} N_{D E P}\left(1+N_{D E P}\right) .
$$

Para validar e verificar o MMD proposto neste trabalho foram resolvidos diversos problemas modelos que representam simplificações de empreendimentos e/ou cascatas de usinas hidrelétricas. Os testes consistiram na simulação da falha de alguns CBNs para observar a resposta do método ante estas situações. Em todas as simulações realizadas os resultados obtidos pelo MMD foram satisfatórios e corresponderam com o estado de disponibilidade global do sistema. A coerência dos resultados foi comprovada pela análise da matriz de dependência resultante, e pela comparação com o método de Árvore de Falhas. Os futuros desdobramentos deste trabalho incluem a comparação do MMD com métodos quantitativos baseados em cadeias de Markov e o aprimoramento da implementação para aumentar o desempenho computacional.

Palavras-chave: Usinas Hidrelétricas, Método de Matrizes de Dependências, Algoritmos de Varredura, Análises de Disponibilidade.

\section{Referências}

[1] Ministério de Minas e Energia, Anuario estatístico de energia elétrica 2013.

[2] British Standards Institution, PAS 55 Asset management. Specification for the optimized management of physical assets, 2008.

[3] G. Fornari, G. Monné Alfaro and D. Sanchez Domingues, Análises de disponibilidade em sistemas de usinas hidrelétricas utilizando matrizes de dependência, 2013.

[4] T. H. Cormen, C. E. Leiserson and R. R. L, Introduction to algorithsm, 2nd ed., 2001.

[5] D. S. Dominguez and J. R. Oliva, Segurança e Confiabili-dade em Sistemas Industriais - Princípios Básicos 2011, JM Editora Ltda. Salvador, 2011, p. 108.

[6] W. Wang and J. M. Loman, "Reliability Block Diagram Simulation Techniques Applied to the IEEE Std. 493 Standard Network," IEEE Transactional on industry aplications, vol. 40, no. 3, 2004.

[7] H. Wang, "A survey of maintenance policies of deteriorating systems," Europen Journal of Operation Research, vol. 139, pp. 469-489, 2002. 